\title{
Clay and Soil Photolysis of the Pesticides Mesotrione and Metsulfuron Methyl
}

\author{
Marie Siampiringue, ${ }^{1}$ Pascal Wong Wah Chung, ${ }^{1,2}$ Moursalou Koriko, ${ }^{3}$ \\ Gado Tchangbedji, ${ }^{3}$ and Mohamed Sarakha ${ }^{1}$ \\ ${ }^{1}$ Institut de Chimie de Clermont-Ferrand, Clermont Université and Université Blaise Pascal, Equipe Photochimie, \\ BP 80026, 63171 Clermont Ferrand, France \\ ${ }^{2}$ Clermont Université, ENSCCF, BP 10448, 63171 Clermont Ferrand, France \\ ${ }^{3}$ Laboratoire GTVD, Faculté des Sciences, Université de Lomé, 05 BP 796, Lomé, Togo
}

Correspondence should be addressed to Mohamed Sarakha; mohamed.sarakha@univ-bpclermont.fr

Received 31 July 2013; Revised 21 November 2013; Accepted 5 December 2013; Published 29 January 2014

Academic Editor: Teodoro Miano

Copyright (C) 2014 Marie Siampiringue et al. This is an open access article distributed under the Creative Commons Attribution License, which permits unrestricted use, distribution, and reproduction in any medium, provided the original work is properly cited.

Photolysis may represent an important degradation process of pollutants at the surface of soil. In the present work, we report a detailed study on the degradation of two pesticides: mesotrione and metsulfuron methyl using a sunlight simulator. In a first step, we studied the photochemical behaviour at the surface of clays from the kinetic as well as from the analytical point of view. In both cases, the quantum yields were found to be higher when compared to those obtained in aqueous solutions. The effect of iron(III), water, and humic substances contents was studied. In the former cases, an increase of the degradation rate was observed while an inhibition was observed with the latter owing to a filter effect phenomenon. In a second step, we studied the photodegradation at the surface of natural soil and identified the generated byproducts. They appear to mainly arise from photohydrolysis process.

\section{Introduction}

Chemicals such as pesticides can be introduced into the environment as a result of their application for plant protection. Thus, the contamination of groundwater, rivers, soils, and also atmosphere is an inevitable effect of their application. The negative ecological consequences related to these contaminants are often assigned to their residence time and bioavailability. Owing to these environmental effects, there is an increase of the research activities toward the methods which could help in the study of the fate and also the elimination of such substrates. In recent years, various methods for water or air purification as well as soil decontamination have been developed including chemical, electrochemical, or photochemical processes [1-5]. In several cases, sunlight degradation may represent one of the main destructive pathways for pesticides after their application into the environment. Since several kinds of these contaminants present absorption spectra with a nonnegligible overlap with that of solar light, an inexhaustible source, the photochemical process becomes of great interest. Under such conditions they can easily undergo photochemical transformation upon exposure to the solar light by direct absorption, namely, direct process $[4,6$, 7]. This also leads to the formation of various by-products that can be more harmful than the parent compound. In the case where the contaminants do not absorb solar light, they may still undergo phototransformation through indirect reactions. In this case, other substances, added or naturally present in a specified medium, play the role of photoinducers or/and photosensitizers [8-12]. Thus, reactive species, such as excited states and reactive oxygen species (ROS), permit the degradation of the target pollutants.

Indirect photochemical processes may also occur at the surface of soils owing to the presence of organic matter originating from plant debris in various stages of decay $[9,10]$. Such substance may contribute for the degradation of the pesticide through the formation of reactive species, such as 
hydroxyl radicals [13] or singlet oxygen [14] or be involved as inhibitors by a screen effect phenomenon.

These processes may of course occur in aqueous solutions, in the atmosphere, on plant leaves, and at the surface of soils. The latter medium can be considered as an ultimate reservoir for pesticides whether they are applied directly or received indirectly from spray drift and residues of treated sites. It is worth noting that in sunlight exposed sites, photochemical reactions at the atmosphere-soil interface may represent important degradation pathways. They may easily dominate other degradation pathways that are normally favoured in the bulk soil [15]. Since soil support is a highly heterogeneous and unmixed medium compared with solution, it is obvious that several photophysical and/or photochemical processes as well as spectroscopic features will then be affected. Thus, pesticide fate in the soils has received much attention due to its effect (dissipation, bio- and photodegradation, transfer process, adsorption processes, etc.). Concerning the photochemical transformations, direct photolysis depends on the light penetration which cannot be precisely defined. Due to light attenuation, the direct photolysis rates are slower when compared to solution [16]. The soil texture may also be of great importance in the degradation process of pesticides. In the case of quinalphos, for example, see Gonçalves et al. [17].

In the present paper we examined the photolysis of two pesticides: mesotrione and metsulfuron methyl (Figure 7) at the surface of the clay Kaolinite, taken as a model surface, and also at the surface of soils with and without organic matter.

Mesotrione is a member of the triketone family of herbicides which is developed for use in maize culture as a substitute for atrazine [18]. It is absorbed both by roots and foliage which allows its use as preemergence or postemergence herbicide. Its photochemical behaviour was deeply studied in pure and natural waters upon simulated solar light irradiation [19]. The main generated by-products are 4-(methylsulfonyl)-2-nitrobenzoic acid, 1,3-diketo 3-(2nitro-4-methylsulfonylphenyl)butanoic acid, and 5,7-diketo7-(2-nitro-4-methylsulfonylphenyl)-heptanoic acid (Figures 8 and 9$)$.

Metsulfuron methyl belongs to the sulfonylurea group which presents an important role in modern agriculture because of its significant action in plant protection. It presents a high selectivity against a wide range of plants. As has been already reported for most sulfonylurea products, in aqueous solutions, hydrolysis was shown to be a significant pathway for their degradation [20-22] (Figure 10). This is obviously owing to the presence in their molecular structure of many functional groups that are subject to hydrolytic reactions. To our knowledge, their photochemical behaviour at the surface of soil is not known. However, studies have been reported on glass surface under sunlight and ultraviolet (UV) light [23] where the half-lives of metsulfuron methyl under UV light and sunlight were found to be 0.5 and 7.8 days, respectively. The major products were identified as methyl-2-sulfonylamino benzoate, 2-amino-6-methoxy4-methyltriazine, and saccharin (O-sulfobenzoimide) (Figure 11).

\section{Experimental Section}

All the used reactants were of the highest grade available. They were used as received. Mesotrione and metsulfuron methyl were from Riedel de Haën. The abbreviations mentioned in Figure 7 were used throughout all the text.

Kaolinite, iron(III) perchlorate, and humic acid were purchased from Fluka, Bentonite, and Montmorillonite from Aldrich. All solutions were prepared with deionised ultrapure water which was purified with Milli-Q device (Millipore) and its purity was controlled by its resistivity. Soil sample (top $5 \mathrm{~cm}$ ) was collected nearby Orange region (South of France). Its characteristics are $\mathrm{pH}=7.7$, natural organic matter $3.2 \%$, Clay $31 \%$, Limon $44.2 \%$, and sand $24.8 \%$. It was dried in the oven at a temperature of $80^{\circ} \mathrm{C}$ and sterilized by 5 autoclaving cycles for two days $\left(P=2 \mathrm{bar}, T=121^{\circ} \mathrm{C}\right)$. The removal of the natural organic matter (NOM) was carried out on sterilized soil. $45 \mathrm{~g}$ of soil was mixed and stirred with $100 \mathrm{~mL} \mathrm{NaOH}$ $(12 \mathrm{M})$ at room temperature for $1 \mathrm{~h}$. Then, $400 \mathrm{~mL}$ of pure water was added for washing and the mixture was stirred for $30 \mathrm{~min}$ and decanted for another $30 \mathrm{~min}$. The supernatant was afterwards removed and another $400 \mathrm{~mL}$ of water were added for washing the solid. Such water cleaning step was repeated 4 times and then the solution was neutralized by the addition of perchloric acid solution $(1.0 \mathrm{M})$ in order to reach a $\mathrm{pH}$ around to 6.2-6.9. After such procedure the amount of organic carbon was estimated to be about $0.5 \%$. The soil sample was spiked with a methanol solution of the pesticide at a known concentration, mixed vigorously, and then air-dried. $200 \mathrm{mg}$ of this mixture was then deposited in a Teflon mold supported by a glass slide to obtain a film of roughly $1 \mathrm{~mm}$ thickness with a flat surface.

The preparation of the clay layer $(2.5 \mathrm{~cm} \times 1.5 \mathrm{~cm})$ was performed on a Pyrex glass as described in the literature [24]. In our case, the clay slurry with the desired amount of clay and defined concentration of substrate (mesotrione or metsulfuron methyl) was prepared in methanol. After deposition of a known volume on the Pyrex glass, the slurry was allowed to dry overnight at room temperature. The layer thickness of the sample was determined according to the dry amount of Kaolinite deposited on the Pyrex plate, the surface area, and the bulk density, $\rho_{\text {bulk }}$, of the layer $\left(\rho_{\text {bulk Kaolinite }}=1.8[25]\right)$. With this procedure, layers of various thicknesses were obtained: from $15 \mu \mathrm{m}$ to $200 \mu \mathrm{m}$. The irradiation of the dry sample was performed by using a Pyrex tube (roughly $20 \mathrm{~cm}^{3}$ ) as a reactor. For each irradiation time, two different sample plates were used. The layer was quantitatively collected and mixed with $2 \mathrm{~mL}$ of methanol. The mixture was gently agitated for 10 minutes at room temperature. After centrifugation at $3500 \mathrm{rpm}$ for 10 minutes, the HPLC analysis showed that more than $95 \%$ of product recovery was obtained.

Sunlight simulated experiments were conducted using a Suntest CPS photosimulator (Atlas) equipped with a Xenon lamp. This contains a glass filter restricting the transmission of wavelengths below $290 \mathrm{~nm}$. The equipment was used with a setting of $500 \mathrm{~W} / \mathrm{m}^{2}$. In order to work at constant temperature (roughly $20^{\circ} \mathrm{C}$ ), cold water flowed through the bottom of the Suntest photosimulator. Prior to kinetic and 


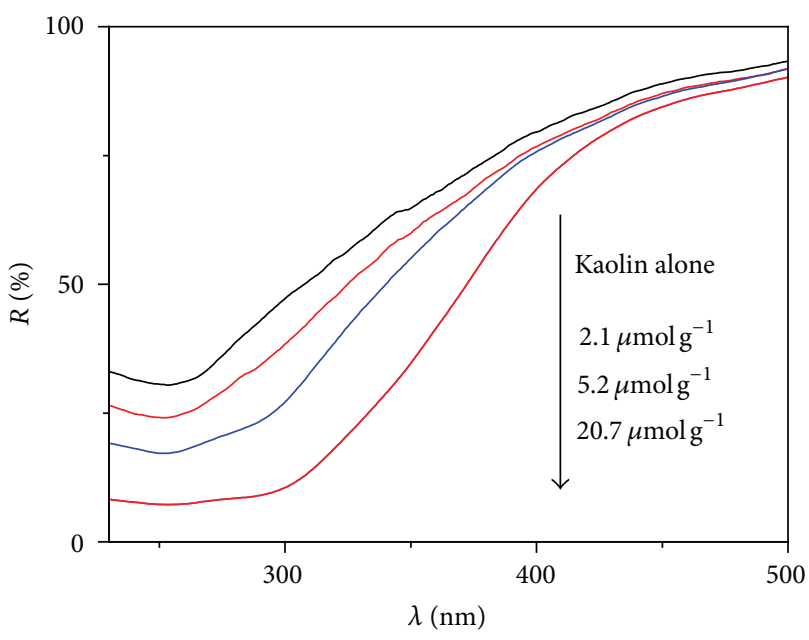

(a)

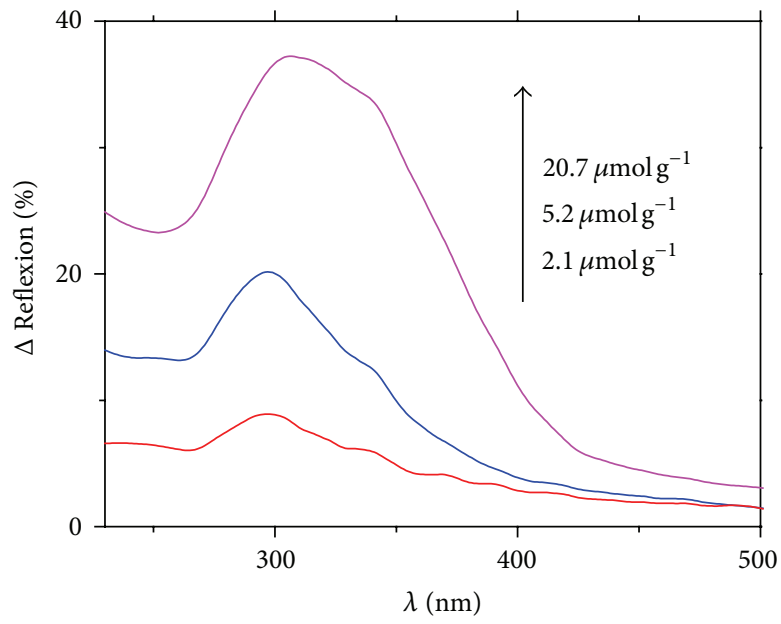

(b)

FIGURE 1: (a) Diffuse reflectance of mesotrione at the surface of Kaolinite as a function of concentration. (b) The reflection spectrum owing to the organic compound mesotrione. Film thickness: $200 \mu \mathrm{m}$.

analytical measurements, actinometries using p-nitroanisole as chemical actinometers [26] and also by using a radiometer (Ocean Optics QE65000) were undertaken in order to check for the uniformity of light distribution within all the surface of Suntest simulator. Within the experimental error (less than $4 \%)$, the light emitted from the Xenon lamp was found to be perfectly homogeneous.

The transformation of the substrates and the formation of the byproducts were monitored by analytical HPLC using a Waters apparatus equipped with a 996-photodiode array detector. The HPLC analyses were conducted by using a reverse phase Merck column (Spherisorb ODS-2, $250 \mathrm{~mm} \times$ $4.6 \mathrm{~mm}, 5 \mu \mathrm{m})$. The flow rate was $1.0 \mathrm{~mL} \mathrm{~min}^{-1}$ and the injected volume was $50 \mu \mathrm{L}$. The mobile phase consisted of acidified water (acetic acid $0.01 \%$ ) and acetonitrile ( $7 / 3$ by volume) in the case of mesotrione and water (acetic acid $0.01 \%$ ) and methanol (6/4 by volume) for metsulfuron methyl.

UV-Vis diffuse reflectance and transmittance of clay layers were recorded with a Cary 300 scan (Varian) equipped with integrating sphere (DRA-CA-30I; $70 \mathrm{~mm}$; Varian). The spectra were recorded within the range $230-800 \mathrm{~nm}$. The recorded reflectance was corrected by using Spectralon's (Labsphere) absolute reflectance.

LC/MS studies were carried out with a Waters Q-TOF Micro, mass spectrometer equipped with a Waters Alliance HPLC system from CRMP Center (Centre Regionale de Measures Physique) at the University Blaise Pascal. It is equipped with an electrospray ionisation source (ESI) and a Waters photodiode array detector. Each single experiment permitted the simultaneous recording of both UV chromatogram at a preselected wavelength and an ESI-MS full scan. Data acquisition and processing were performed by MassLynx NT 3.5 system. Chromatography was run using a Nucleosil column $100-5 \mathrm{C} 18$ ec $(250 \times 4.6 \mathrm{~mm}, 5 \mu \mathrm{m})$. Samples $(5-$ $10 \mu \mathrm{L}$ ) were injected either directly or after evaporation of the solvent for better detection. The following gradient program
TABLE 1: Gradient program.

\begin{tabular}{lccccc}
\hline Time, minutes & Initial & 3 & 13 & 20 & 30 \\
\hline$\% \mathrm{~A}$ & 95 & 80 & 80 & 5 & 95 \\
$\% \mathrm{~B}$ & 5 & 20 & 20 & 95 & 5 \\
\hline
\end{tabular}

was used by employing water with $0.4 \%$ acetic acid (A) and acetonitrile (B) at $1 \mathrm{~mL} \mathrm{~min}^{-1}$ (Table 1 ).

\section{Results}

Reflection-Diffuse Spectrum. The absorption spectrum of mesotrione in aqueous solution at $\mathrm{pH}=6.5$ shows an intense band with a maximum at $255 \mathrm{~nm}$ and a shoulder at $285 \mathrm{~nm}$ more likely attributed to the $\pi-\pi^{*}$ and $n-\pi^{*}$ electronic transitions, respectively [19]. When the diffuse-reflectance spectrum is recorded at the surface of dry Kaolinite with a film thickness of $200 \mu \mathrm{m}$, a decrease of the percentage of reflected light was observed at $\lambda<500 \mathrm{~nm}$ when the concentration of mesotrione increased within the range 2.1-21.0 $\mu \mathrm{mol} \mathrm{g}^{-1}$ (Figure 1(a)). By taking into account the diffuse-reflectance owing to the Kaolinite support, a welldefined and large band was observed with a maximum at $299 \mathrm{~nm}$ (Figure 1(b)). A close analysis of the spectrum also indicates the presence of a shoulder at roughly $330 \mathrm{~nm}$. When compared to the UV spectrum recorded in aqueous medium [19], an important bathochromic shift of about $\Delta \lambda=$ $44 \mathrm{~nm}$ was observed for both electronic transition bands. It is worth noting that the absorption band appears to be broader when the concentration of mesotrione increased. The observed bathochromic shift when comparing spectra in aqueous solutions and at the surface of Kaolinite is more likely related to the interaction between the organic substrates inserted within the various sites of Kaolinite. However, the observed broad band is owing to the various environments 


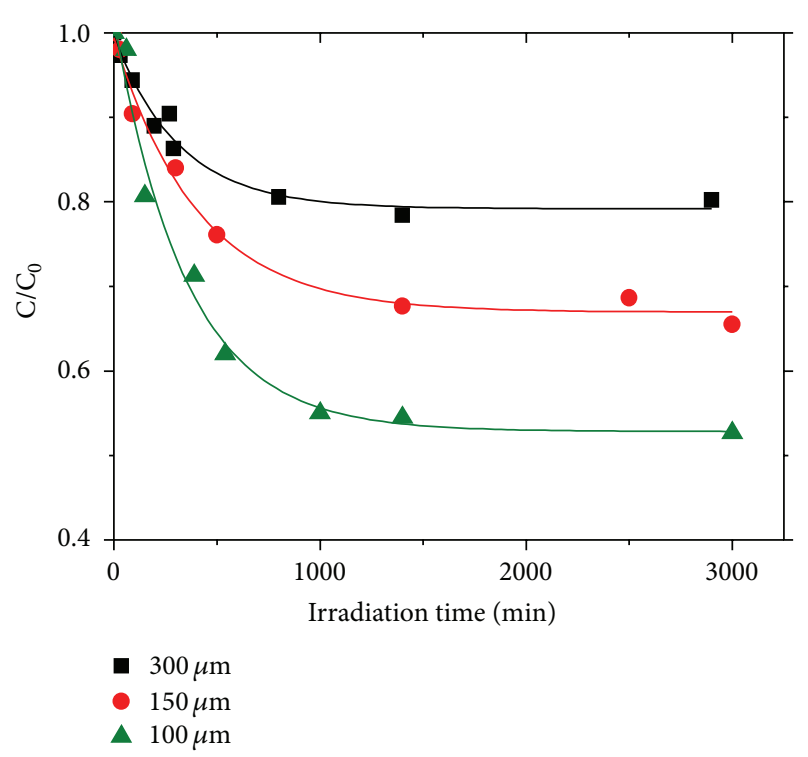

FIGURE 2: Degradation of mesotrione at the surface of various thicknesses of Kaolinite. Irradiation performed in Sunlight simulator. [Mesotrione $]=5.2 \mu \mathrm{mol} \mathrm{g}^{-1}$.

of mesotrione that can be present in various sites but also in a multilayer disposition as observed with other organic substrates $[24,25]$. It should be noted that similar changes were observed by using montmorillonite and bentonite as clays supports where the bathochromic shift was evaluated to be 35 and $39 \mathrm{~nm}$, respectively. In the case of metsulfuron methyl, similar changes were observed within the concentration 3.5-21.0 $\mu \mathrm{mol} \mathrm{g}^{-1}$. The bathochromic shift was evaluated to $20 \mathrm{~nm}$.

Photodegradation at the Surface of Kaolinite. Plates containing films of various and controlled thicknesses of a mixture Kaolinite/mesotrione were irradiated with sunlight simulator. The photochemical disappearance of mesotrione, extracted from Kaolinite using methanol, is shown in Figure 2. The conversion was clearly dependent on the layer thickness. It increased when the thickness decreased in complete agreement with the light attenuation within the clay layer. The degradation was fitted using a first-order kinetics and the rate constant was evaluated to be $4.0 \times 10^{-3} \pm 0.2 \times 10^{-3} \mathrm{~min}^{-1}, 3.0 \times$ $10^{-3} \pm 0.5 \times 10^{-3} \mathrm{~min}^{-1}$, and $2.5 \times 10^{-3} \pm 0.3 \times 10^{-3} \mathrm{~min}^{-1}$ for $100 \mu \mathrm{m}, 160 \mu \mathrm{m}$, and $300 \mu \mathrm{m}$, respectively. It should be noted that by using a layer thickness of roughly $20 \mu \mathrm{m}$, a conversion of about $90 \%$ was reached within 6 hours irradiation time. Under these conditions, the half-life time was estimated to be about 1.5 hour. The quantum yield of degradation was evaluated by using the method reported in the literature [25]. It was estimated under our experimental conditions to $5.0 \times 10^{-4}$ which is approximately one order of magnitude higher than that obtained in aqueous solution [19]. This is more likely owing to several factors such as (i) change in the chemical environment; (ii) more efficient absorption of excitation light due to the change in the absorption spectrum, namely, the bathochromic shift. Similar
TABLE 2: The effect of moisture, iron(III), and humic substances at the surface of Kaolinite on the photodegradation rate constant of mesotrione and metsulfuron methyl; layer thickness $=100 \mu \mathrm{m}$; (organic compound) $=5.2 \mu \mathrm{mol} \mathrm{g}^{-1}$. Irradiation was performed with a Sunlight simulator.

\begin{tabular}{lcccc}
\hline Compound & $\begin{array}{c}\text { Dry layer } \\
\times 10^{-2} \\
\mathrm{~min}^{-1}\end{array}$ & $\begin{array}{c}\text { Moisture } \\
\times 10^{-2} \\
\mathrm{~min}^{-1}\end{array}$ & $\begin{array}{c}\text { Iron(III); } \\
1.0 \mathrm{wt} \% \\
\times 10^{-2} \\
\mathrm{~min}^{-1}\end{array}$ & $\begin{array}{c}\text { Humic acids; } \\
2.0 \mathrm{wt} \% \\
\times 10^{-2} \\
\mathrm{~min}^{-1}\end{array}$ \\
\hline $\begin{array}{l}\text { Mesotrione } \\
\begin{array}{l}\text { Metsulfuron } \\
\text { methyl }\end{array}\end{array}$ & 0.40 & 0.92 & 0.73 & 0.12 \\
\hline
\end{tabular}

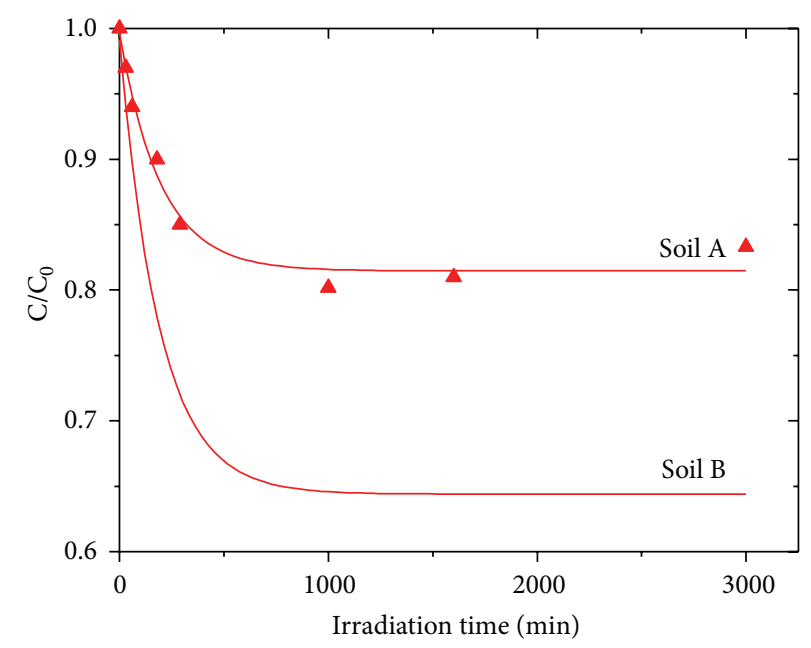

Figure 3: Degradation of mesotrione at the surface of soil A and soil B. Irradiation performed in Sunlight simulator. [Mesotrione] = $5.2 \mu \mathrm{mol} \mathrm{g}{ }^{-1}$. Thickness $1 \mathrm{~mm}$.

behaviour was observed with metsulfuron methyl for which the quantum yield was estimated to be $8.0 \times 10^{-3}$ compared to $3.0 \times 10^{-3}$ in aqueous solution.

Effect of Moisture, Humic Substances, and Iron(III) Contents. The effect of the main components of soil such as moisture, humic substances, and iron(III) was studied. All the results are gathered in Table 2. The percentage of moisture was increased by adding $100 \mu \mathrm{L}$ of pure water at the surface of the sample (layer $=100 \mu \mathrm{m})$. This was repeated after each 1 hour of irradiation. For mesotrione, the rate constant was estimated to be $9.2 \times 10^{-3} \mathrm{~min}^{-1}$ which is 2.5 times higher than in relatively dry conditions, while, for metsulfuron methyl, an increase by one order of magnitude was observed. This can be explained first by a change in the chemical environment permitting the occurrence of some new reaction pathways that could be minor on dry clays and also by a change in the light penetration as well as organic compounds diffusion into humid Kaolinite [25]. It is important to note that under these conditions, no thermal degradation was observed when the sample was kept in the dark.

The addition of iron(III) species at a concentration of $1.0 \mathrm{wt} \%$ permitted a better degradation of both compounds 


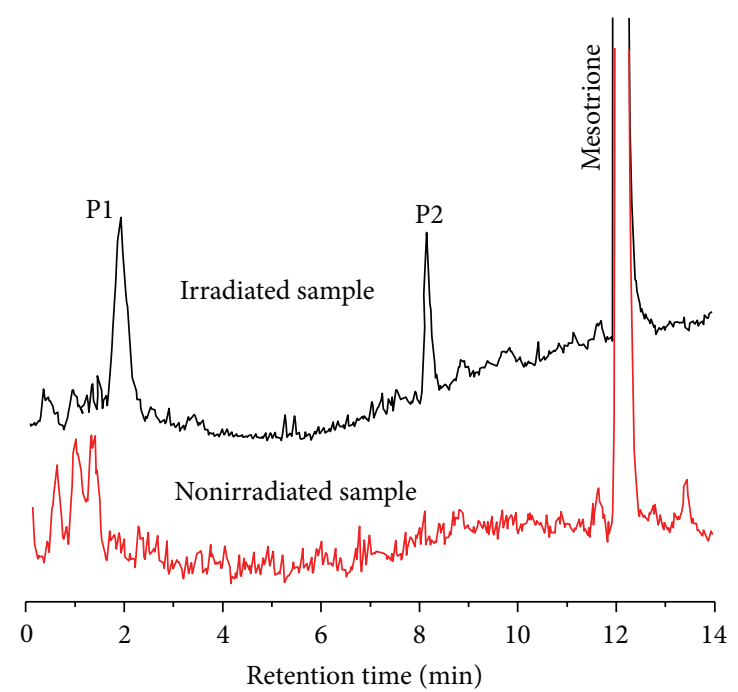

(a)

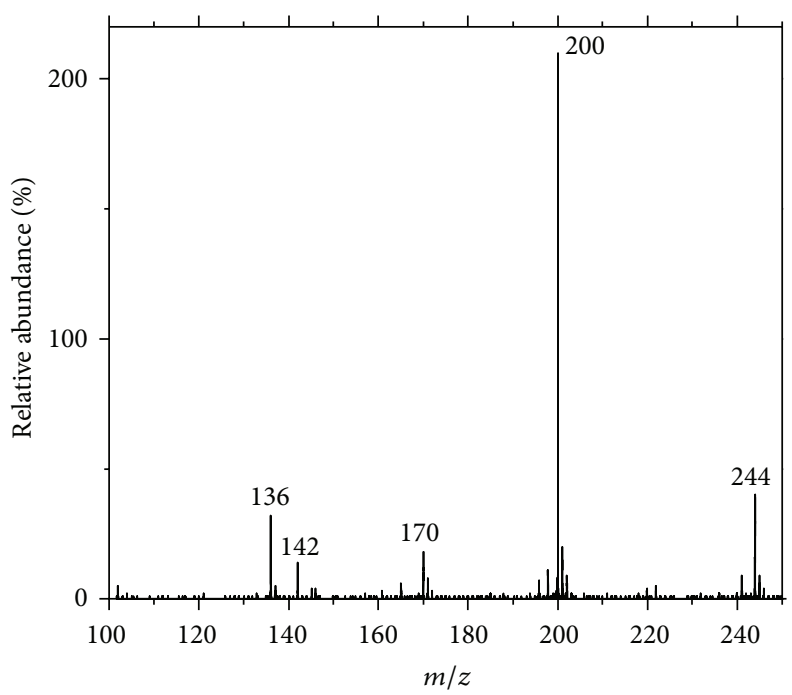

(b)

Figure 4: (a) HPLC chromatogram of a solution obtained by extraction with methanol of an irradiated mixture mesotrione/Kaolinite at $\lambda_{\max }=250 \mathrm{~nm}$ using a gradient program (see Section 2). (b) Mass spectrum of product P1. [Mesotrione] $=5.2 \mu \mathrm{mol} \mathrm{g}{ }^{-1}$. Irradiation was performed in a Sunlight simulator.

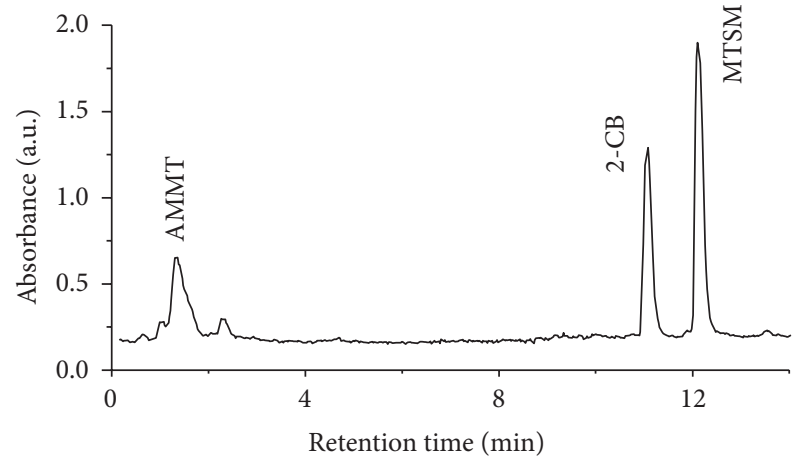

FIGURE 5: HPLC chromatogram of a solution obtained by extraction with methanol of an irradiated mixture MTSM/Kaolinite $[\mathrm{MTSM}]=$ $5.2 \mu \mathrm{mol} \mathrm{g}^{-1}$. Detection at $\lambda_{\max }=250 \mathrm{~nm}$ using a gradient program (see Section 2). Irradiation was performed in a Sunlight simulator.

with an increase by a factor of 2 for mesotrione and 6 for metsulfuron methyl. This is more likely due to direct excitation of the substrate as observed above but also the involvement of photoinduced reactions that represent additional efficient processes as already observed with the irradiation of fenamiphos [27] as well as azinphos methyl [28] at the surface of Kaolinite. In fact iron(III), more likely as aqua complex species, absorbs the used excitation light (>290 nm) and permits the generation of the hydroxyl radical species (1) [29-31]. The latter species is known for its efficient reactivity toward the majority of the organic compounds [32]:

$$
\left[\mathrm{Fe}\left(\mathrm{H}_{2} \mathrm{O}\right)_{5} \mathrm{OH}\right]^{2+} \stackrel{\mathrm{h} v}{\longrightarrow} \mathrm{Fe}^{2+}+{ }^{\circ} \mathrm{OH}+\mathrm{H}_{2} \mathrm{O}
$$

The effect of humic substances was studied at a concentration of $2.0 \mathrm{wt} \%$ that corresponds to an average content

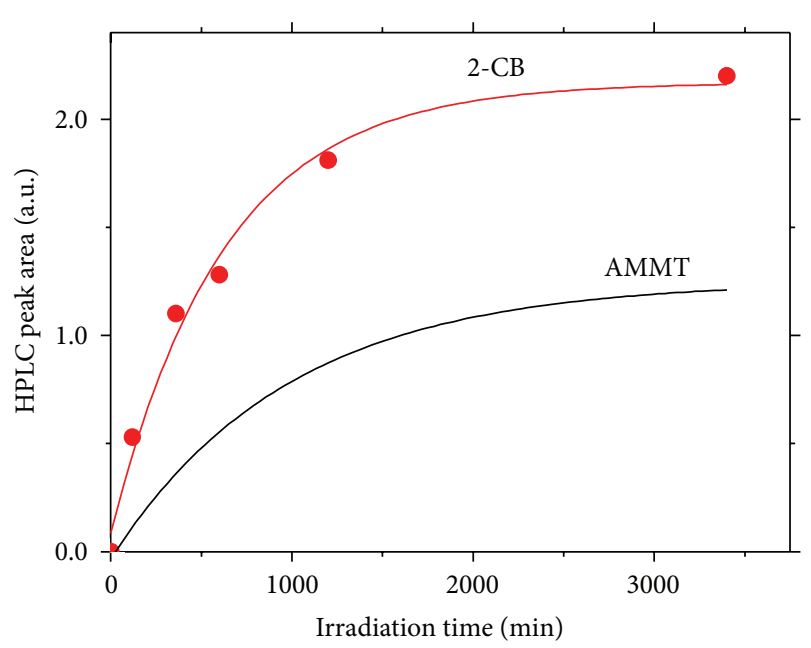

FIgure 6: Formation of products 2-CB and AMMT upon excitation of metsulfuron methyl (MTSM) at the surface of Kaolinite. MTSM/Kaolinite $[\mathrm{MTSM}]=5.2 \mu \mathrm{molg}^{-1}$. Detection at $\lambda_{\max }=$ $250 \mathrm{~nm}$. Irradiation was performed in a Sunlight simulator.

of humic substances in soil. Under these conditions, the degradation occurred but the rate significantly decreased by a factor of roughly 3 in the case of mesotrione and a factor of 2 for metsulfuron methyl. This detrimental effect may be explained by (i) an efficient interaction of humic acids with the excited states of the organic compounds leading to their efficient deactivation through electron or/and energy transfer processes and (ii) a competition in light absorption owing to the increase of the absorbance in the presence of humic substances as already observed with the irradiation of fenamiphos [27] as well as azinphos methyl [28] at the surface of kaolinite. It should be pointed out that dark control 
<smiles>COS(=O)(=O)c1ccc(C(=O)C2C(=O)CCCC2=O)c([N+](=O)[O-])c1</smiles>

Mesotrione (MES)<smiles>COC(=O)c1ccccc1S(=O)(=O)NC(=O)Nc1nc(C)nc(OC)n1</smiles>

Metsufuron methyl (MTSM)

FiguRe 7<smiles>COS(=O)(=O)c1ccc(C(=O)O)c([N+](=O)[O-])c1</smiles>

4-(Methylsulfonyl)-2-nitrobenzoic acid

Figure 8<smiles>COS(=O)(=O)c1ccc(C(=O)CC(=O)O)c([N+](=O)[O-])c1</smiles>

1,3-Diketo-3-(2-nitro-4-methylsulfonylphenyl) propanoic acid

Figure 9

experiments showed that no degradation of both substrates was observed in the presence of iron(III) species or humic substances.

Photodegradation at the Surface of Soil. The photodegradation by excitation with a sunlight simulator of both pesticides (at $5.2 \mu \mathrm{mol} \mathrm{g}^{-1}$ ) was also explored at the surface of natural soil. It was performed using soil with (soil A) and without natural organic matter (soil B) (see Section 2). As shown in Figure 3, the degradation of the pesticides also occurred at the surface of the used soil with a rate constant that depends on the amount of NOM. This was evaluated to be $5.8 \times 10^{-4} \mathrm{~min}^{-1}$ and $1.4 \times 10^{-3} \mathrm{~min}^{-1}$ with soil $\mathrm{A}$ and soil $\mathrm{B}$, respectively. This aspect is directly linked to the amount of NOM in the sample. The more organic matter we have, the lower rate constant is obtained as already observed in the presence of humic substances. It is important to note that the conversion percentage rapidly levelled off and no degradation is observed after 1000 minutes irradiation time. These conclusions suppose that the NOM removal procedure did not change soil mineral characteristics.

Photoproducts Analyses. The analysis of the mixture, extracted with methanol, was performed by using HPLC and HPLC/MS techniques. Figure 4 presents a chromatogram that was obtained for mesotrione at the surface of Kaolinite.
Besides the parent compound, it shows the presence of two main products, $\mathrm{P} 1$ and $\mathrm{P} 2$, with shorter retention times indicating the formation of more polar compounds.

Product P1 presents a retention time of about 2 minutes. By LC/ESI in negative mode, its molecular ion is $m / z=244$. It is similar to that obtained by direct excitation of mesotrione in aqueous solution and corresponds to 4-(methylsulfonyl)2-nitrobenzoic acid (MNBA) [19]. It leads by decarboxylation process to an intense ion at $m / z=200$ (Figure 4(b)).

Product P2 has a retention time of 8.8 minutes and presents an intense ion at $m / z=242$. Such ion appears to be a daughter ion from the parent ion $m / z=286$ via a decarboxylation process. This product was also observed when mesotrione was irradiated in aqueous solution [19]. It was identified as 1,3-diketo-3-(2-nitro-4-methylsulfonylphenyl) propanoic acid.

Both products are the result of an photohydrolysis process according to Scheme 1.

When metsulfuron methyl was used, two main products were obtained (Figure 5). They were identified as 2(carbomethoxy) benzenesulfonamide (2-CB) and 2-amino4-methoxy-6-methyl-1,3,5-triazine (AMMT) by comparing the retention time with authentic samples. They result from the hydrolysis of the group at the bridge moiety as observed in aqueous solutions [29]. 2-CB and AMMT appeared to be formed from the early stages of the irradiation and increased as a function of irradiation time (Figure 6).

Since these two products are commercial, we evaluated this hydrolysis process to about $40 \%$. This percentage increased to $60 \%$ when the amount of moisture increased.

These two products were already reported to be formed by studying the photodegradation of metsulfuron methyl on glass surface [23] and were reported to be nonphytotoxic [33]. However, under our experimental conditions we were not able to detect saccharin (O-sulfobenzoimide) which was shown to be formed from 2-CB.

\section{Conclusion}

The photolysis of the pesticides mesotrione and metsulfuron methyl was studied at the surface of clays (Kaolinite) and soil. The degradation process was efficient and depends on soil components such iron(III) species, natural organic matter, and water content. In the case of iron and water, the photodegradation rate increased by increasing their amount owing to the involvement of additional reaction pathways such as hydrolysis and photoinduced reactions. The degradation rate drastically decreased when the natural 
<smiles>COC(=O)c1ccccc1S(=O)(=O)NC(=O)Nc1nc(C)nc(OC)n1</smiles>

Metsulfuron methyl (MTSM)

FIGURE 10<smiles>COC(=O)c1ccccc1S(N)(=O)=O</smiles>

2-(Carbomethoxy) benzenesulfonamide $2-\mathrm{CB}$<smiles>COc1nc(C)nc(N)n1</smiles>

2-Amino-4-methoxy-6-methyl-1,3,5-triazine

AMMT

FIGURE 11

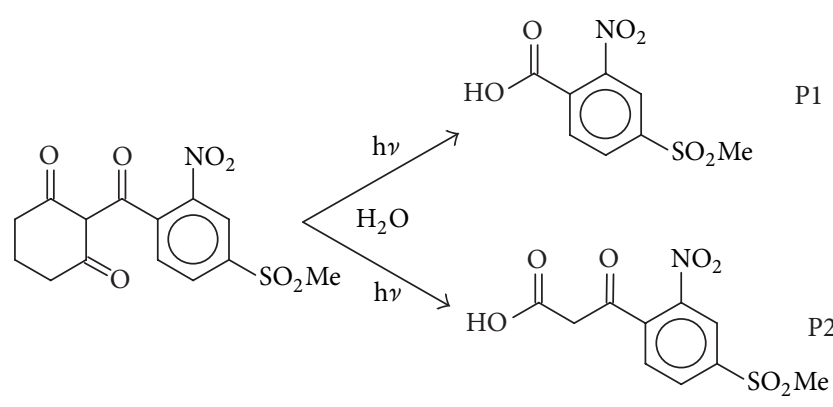

SCHEME 1

organic matter content increased due to an inner filter effect. In the case of both pesticides, the products were similar to those obtained in aqueous solutions. They mainly arise from photohydrolysis processes.

\section{Conflict of Interests}

The authors declare that there is no conflict of interests regarding the publication of this paper.

\section{References}

[1] G. Centi and S. Perathoner, "Remediation of water contamination using catalytic technologies," Applied Catalysis B, vol. 41, no. 1-2, pp. 15-29, 2003.

[2] S. Chiron, A. Fernandez-Alba, A. Rodriguez, and E. GarciaCalvo, "Pesticide chemical oxidation: state-of-the-art," Water Research, vol. 34, no. 2, pp. 366-377, 2000.

[3] H. D. Burrows, M. Canle L, J. A. Santaballa, and S. Steenken, "Reaction pathways and mechanisms of photodegradation of pesticides," Journal of Photochemistry and Photobiology B, vol. 67, no. 2, pp. 71-108, 2002.

[4] E. S. da Silva, P. Wong-Wah-Chung, H. D. Burrows, and M. Sarakha, "Photochemical degradation of the plant growth regulator 2-(1-Naphthyl) acetamide in aqueous solution upon
UV irradiation," Journal of Photochemistry and Photobiology, vol. 89, no. 3, pp. 560-570, 2013.

[5] L. M. Canle, M. I. Fernandez, C. Martinez, and J. A. Santaballa, "Photochemistry for pollution abatement," Pure and Applied Chemistry, vol. 85, no. 7, pp. 1437-1449, 2013.

[6] O. Hutzinger, "Environmental photochemistry," in The Handbook of Environmental Chemistry - Part L, vol. 2, pp. 180-215, Springer, 1999.

[7] O. Legrini, E. Oliveros, and A. M. Braun, "Photochemical processes for water treatment," Chemical Reviews, vol. 93, no. 2, pp. 671-698, 1993.

[8] K. H. Chan and W. Chu, "Effect of humic acid on the photolysis of the pesticide atrazine in a surfactant-aided soil-washing system in acidic condition," Water Research, vol. 39, no. 10, pp. 2154-2166, 2005.

[9] K. Gohre, R. Scholl, and G. C. Miller, "Singlet oxygen reactions on irradiated soil surfaces," Environmental Science and Technology, vol. 20, no. 9, pp. 934-938, 1986.

[10] V. R. Hebert and G. C. Miller, "Depth dependence of direct and indirect photolysis on soil surfaces," Journal of Agricultural and Food Chemistry, vol. 38, no. 3, pp. 913-918, 1990.

[11] C. Martinez, S. Vilarino, M. I. Fernandez, J. Faria, L. M. Canle, and J. A. Santaballa, "Mechanism of degradation of ketoprofen by heterogeneous photocatalysis in aqueous solution," Applied Catalysis B, vol. 142, pp. 633-646, 2013.

[12] M. Piecha, M. Sarakha, and P. Trebše, "Photocatalytic degradation of cholesterol-lowering statin drugs by $\mathrm{TiO} 2$-based catalyst. Kinetics, analytical studies and toxicity evaluation," Journal of Photochemistry and Photobiology A, vol. 213, no. 1, pp. 61-69, 2010.

[13] S. A. Mabury and D. G. Crosby, "The relationship of hydroxyl reactivity to pesticide persistence," in Aquatic and Surface Photochemistry, G. R. Helz, R. G. Zepp, and D. G. Crosby, Eds., chapter 10, Lewis Publishers, Chelsea, Mich, USA, 1994.

[14] K. Gohre and G. C. Miller, "Singlet oxygen generation on soil surfaces," Journal of Agricultural and Food Chemistry, vol. 31, no. 5, pp. 1104-1108, 1983.

[15] C. A. Smith, Y. Iwata, and F. A. Gunther, "Conversion and disappearance of methidathion on thin layers of dry soil," Journal 
of Agricultural and Food Chemistry, vol. 26, no. 4, pp. 959-962, 1978.

[16] G. P. Nilles and M. J. Zabik, "Photochemistry of bioactive compounds. Multiphase photodegradation spectral analysis of basagran," Journal of Agricultural and Food Chemistry, vol. 23, no. 3, pp. 410-415, 1975.

[17] C. Gonçalves, A. Dimou, V. Sakkas, M. F. Alpendurada, and T. A. Albanis, "Photolytic degradation of quinalphos in natural waters and on soil matrices under simulated solar irradiation," Chemosphere, vol. 64, no. 8, pp. 1375-1382, 2006.

[18] G. Mitchell, D. W. Bartlett, T. E. M. Fraser et al., "Mesotrione: a new selective herbicide for nuse in maize," Pest Management Science, vol. 57, pp. 120-128, 2001.

[19] A. T. Halle and C. Richard, "Simulated solar light irradiation of mesotrione in natural waters," Environmental Science and Technology, vol. 40, no. 12, pp. 3842-3847, 2006.

[20] H. M. Brown, "Mode of action, crop selectivity, and soil relations of the sulfonylurea herbicides," Pesticide Science, vol. 29, no. 3, pp. 263-281, 1990.

[21] M. E. Beyer, H. M. Brown, and M. J. Duffy, "Sulfonylurea herbicide soil relations," Proceedings of the British Crop Protection Conference, vol. 2, pp. 531-540, 1987.

[22] Q. Ye, J. Sun, and J. Wu, "Causes of phytotoxicity of metsulfuronmethyl bound residues in soil," Environmental Pollution, vol. 126, no. 3, pp. 417-423, 2003.

[23] R. Paul and S. B. Singh, "Phototransformation of herbicide metsulfuron methyl," Journal of Environmental Science and Health $B$, vol. 43, no. 6, pp. 506-512, 2008.

[24] M. E. Balmer, K.-U. Goss, and R. P. Schwarzenbach, "Photolytic transformation of organic pollutants on soil surfaces-an experimental approach," Environmental Science and Technology, vol. 34, no. 7, pp. 1240-1245, 2000.

[25] A. Ciani, K.-U. Goss, and R. P. Schwarzenbach, "Photodegradation of organic compounds adsorbed in porous mineral layers: determination of quantum yields," Environmental Science and Technology, vol. 39, no. 17, pp. 6712-6720, 2005.

[26] D. Dulin and T. Mill, "Development and evaluation of sunlight actinometers," Environmental Science and Technology, vol. 16, no. 11, pp. 815-820, 1982.

[27] L. Tajeddine, M. Nemmaoui, H. Mountacer, A. Dahchour, and M. Sarakha, "Photodegradation of fenamiphos on the surface of clays and soils," Environmental Chemistry Letters, vol. 8, no. 2, pp. 123-128, 2010.

[28] M. Menager and M. Sarakha, "Simulated solar light phototransformation of organophosphorus azinphos methyl at the surface of clays and goethite," Environmental Science \& Technology, vol. 47, pp. 765-772, 2013.

[29] S. Rafqah, A. Aamili, S. Nelieu et al., "Kinetics and mechanism of the degradation of the pesticide metsulfuron methyl induced by excitation of iron(III) aqua complexes in aqueous solutions: steady state and transient absorption spectroscopy studies," Photochemical and Photobiological Sciences, vol. 3, no. 3, pp. 296-304, 2004.

[30] H.-J. Benkelberg and P. Warneck, "Photodecomposition of iron(III) hydroxo and sulfato complexes in aqueous solution: wavelength dependence of $\mathrm{OH}$ and $\mathrm{SO}_{4}^{-}$quantum yields," Journal of Physical Chemistry, vol. 99, no. 14, pp. 5214-5221, 1995.

[31] S. Rafqah, G. Mailhot, and M. Sarakha, "Highly efficient photodegradation of the pesticide metolcarb induced by $\mathrm{Fe}$ complexes," Environmental Chemistry Letters, vol. 4, no. 4, pp. 213-217, 2006.
[32] G. V. Buxton, C. L. Greenstock, W. P. Helamn, and A. B. Ross, "Critical review of rate constants for reactions of hydrated electrons, hydrogen atoms and hydroxyl radicals $\left({ }^{\circ} \mathrm{OH} /{ }^{\circ} \mathrm{O}^{-}\right)$in aqueous solution," Journal of Physical and Chemical Reference Data Reprints, vol. 17, no. 2, pp. 513-886, 1988.

[33] Q. Ye, J. Sun, and J. Wu, "Causes of phytotoxicity of metsulfuronmethyl bound residues in soil," Environmental Pollution, vol. 126, no. 3, pp. 417-423, 2003. 

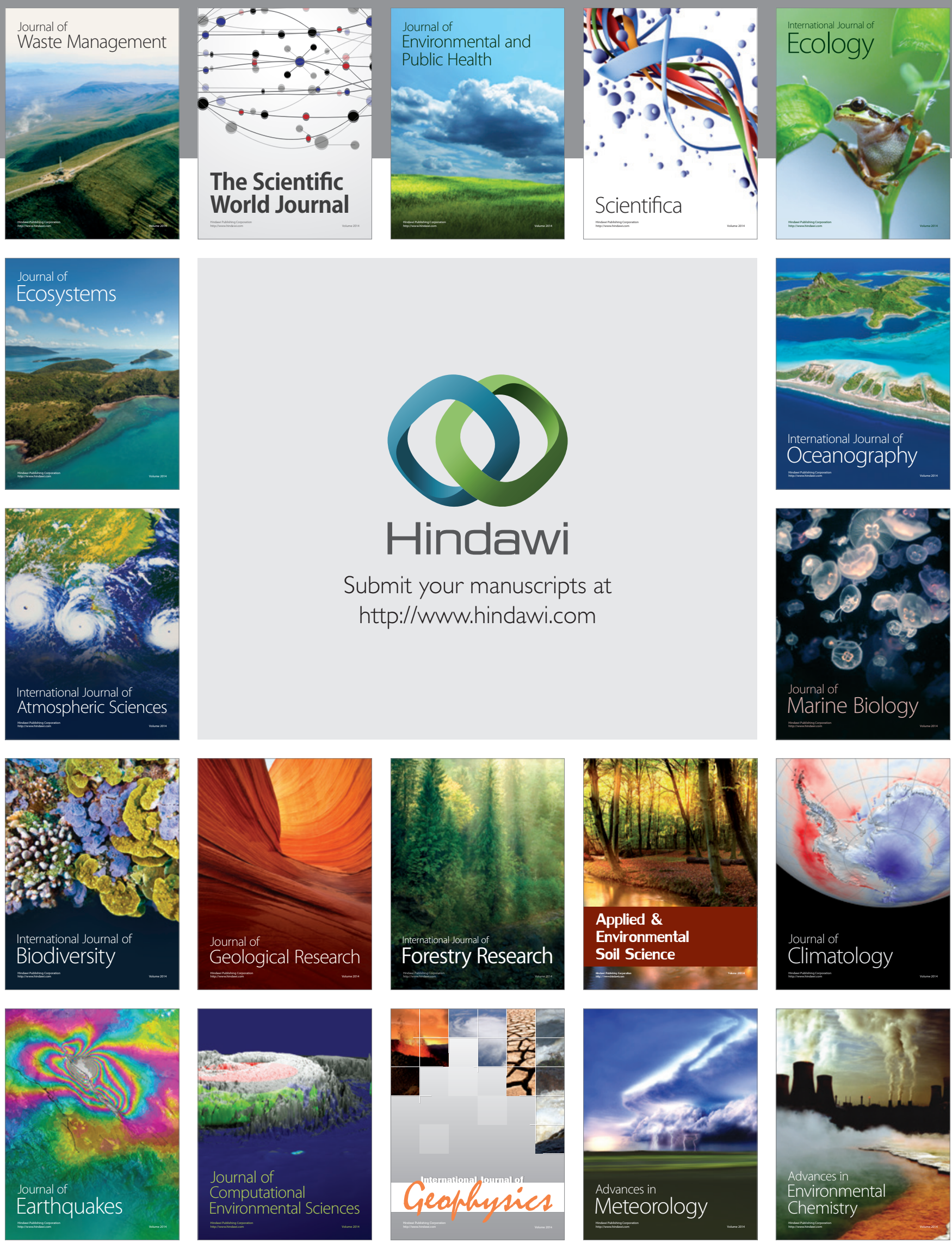